\title{
Avian Influenza Virus Detection Rates in Poultry and Environment at Live Poultry Markets, Guangdong, China
}

Kit Ling Cheng, ${ }^{1}$ Jie Wu, ${ }^{1}$ Wei Ling Shen, Alvina Y.L. Wong, Qianfang Guo, Jianxiang Yu, Xue Zhuang, Wen Su, Tie Song, Malik Peiris, Hui-Ling Yen, ${ }^{2}$ Eric H.Y. Lau ${ }^{2}$

We report the use of environmental samples to assess avian influenza virus activity in chickens at live poultry markets in China. Results of environmental and chicken samples correlate moderately well. However, collection of multiple environmental samples from holding, processing, and selling areas is recommended to detect viruses expected to have low prevalence.

L ive poultry markets (LPMs) can serve as hubs for avian influenza virus (AIV) amplification in poultry and pose a risk for human zoonotic infections (14). Adopting efficient sampling strategies to monitor AIVs with human zoonotic potential at LPMs is essential for zoonotic disease prevention and pandemic preparedness. Recommendations regarding routine surveillance that would robustly and efficiently inform AIV activity at LPMs have been limited (5).

Handling of live poultry interrupts the vending process; moreover, such routine surveillance is difficult to implement. Environmental samples have been collected to monitor AIV activity at LPMs (5-9). There have been limited parallel comparisons of AIV detection rates among poultry and environmental samples $(7,10)$. Without frequent cleaning, the environment often permits AIV accumulation; environmental samples may thus overestimate AIV prevalence in poultry. Subtype-specific detection rates among different environmental samples may also vary. To inform the development of effective sampling strategies for AIV surveillance, we compared monthly detection rates

Author affiliations: University of Hong Kong, Hong Kong,

China (K.L. Cheng, A.Y.L. Wong, W. Su, M. Peiris, H.-L. Yen,

E.H.Y. Lau); Guangdong Provincial Center for Disease Control and Prevention, Guangdong, China (J. Wu, W.L. Shen, Q. Guo,

J. Yu, X. Zhuang, T. Song)

DOI: https://doi.org/10.3201/eid2603.190888 for AIV subtypes H5, H7, and H9 in chickens and various environmental samples at LPMs in Guangzhou, China.

\section{The Study}

During December 2015-July 2018, we performed sampling twice per month at 1 wholesale (52 stalls) and 1 retail (8 stalls) LPM, from 2 randomly selected stalls per sampling event. We collected paired oropharyngeal and cloacal swab samples ( $n=3,119$ chickens) and environmental samples $(n=3,008)$ in viral transport medium at the LPMs (Appendix Figure 1, https:// wwwnc.cdc.gov/EID/article/26/3/19-0888-App1. pdf). We randomly collected samples from all chickens at the selected stalls. We rarely observed sick chickens but we sampled them when identified. We also collected environmental samples from 3 key activity areas: poultry holding zones (fecal droppings, drinking water, and poultry feed), slaughtering zones (defeathering machines and surrounding defeathering working areas), and selling zones (chopping boards and display tables) near the selected chickens whenever possible (5-9). (Stalls sampled at the wholesale LPM [wLPM] have only poultry holding zones.) We sampled air using BC-251 cyclone-based NIOSH bioaerosol samplers that fractionate airborne particles into $>4 \mu \mathrm{m}, 1-4 \mu \mathrm{m}$, and $<1 \mu \mathrm{m}$ size fractions (11). We applied quantitative real-time reverse transcription PCR to detect the matrix gene segment of AIV; we analyzed positive samples by the hemagglutinin gene to determine the AIV subtype (H5, H7, or H9) using specific primers and probes $(12,13)$.

$\mathrm{H} 5, \mathrm{H} 7$, and $\mathrm{H} 9$ detection rates in environmental samples (median monthly difference $6.2 \%$ for $\mathrm{H} 5$,

\footnotetext{
${ }^{1}$ These authors contributed equally to this article.

${ }^{2}$ These senior authors contributed equally to this article.
} 


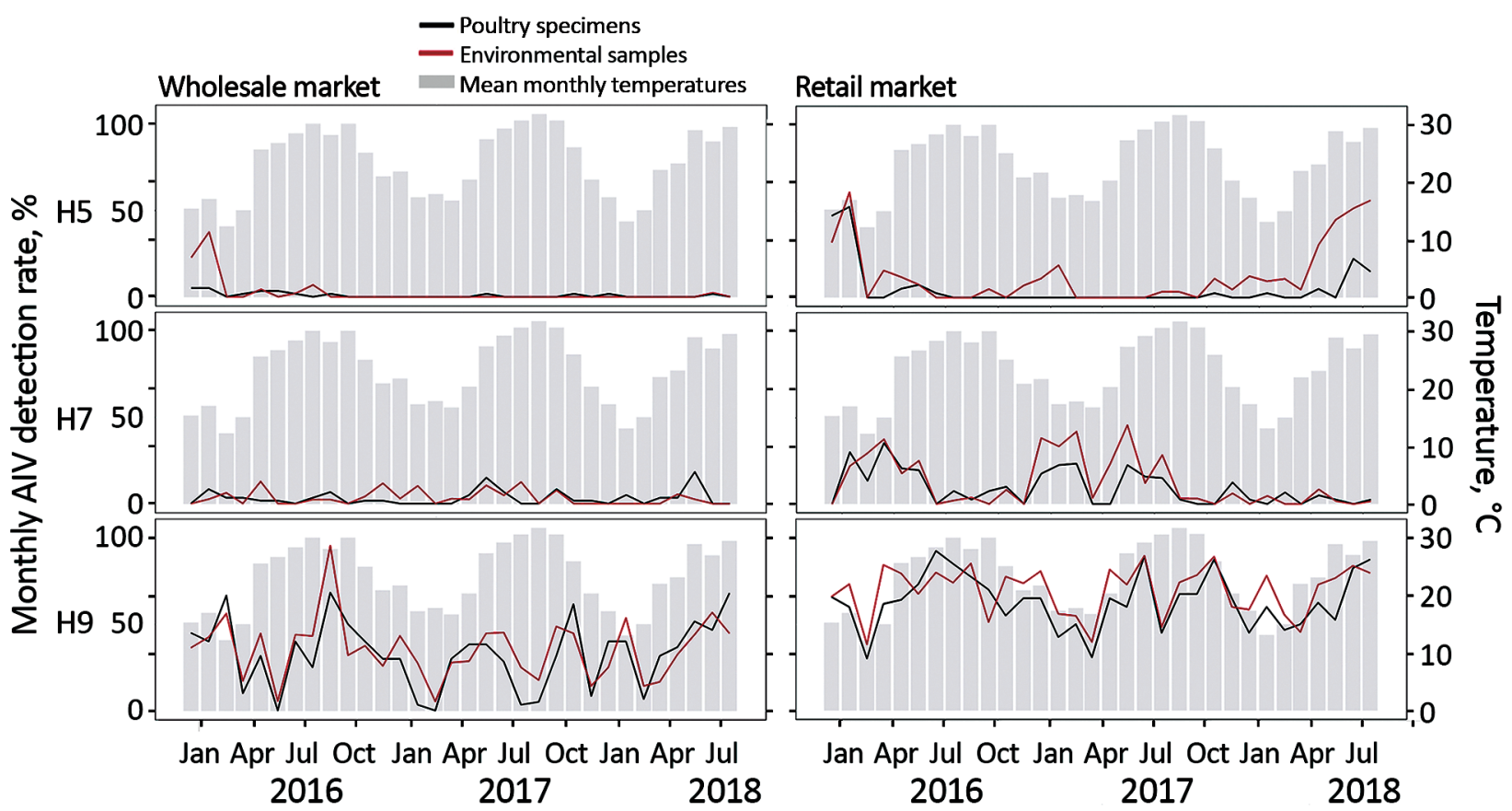

Figure 1. Monthly AIV H5, H7, and $\mathrm{H} 9$ positivity rates detected in poultry and environmental samples at live poultry markets (LPMs), Guangdong, China, December 2015-July 2018. Chicken (oropharyngeal and cloacal swab specimens) and environmental (swab specimens and air samples) samples were collected monthly from 1 retail and 1 wholesale LPM in Guangzhou and tested for H5, H7, and H9 AIV by real-time RT-PCR. Gray bars indicate mean temperatures recorded on the sampling date in Guangzhou. AIV, avian influenza virus.

$3.1 \%$ for $\mathrm{H} 7$, and $34.1 \%$ for $\mathrm{H} 9$; all $\mathrm{p}<0.02$ by MannWhitney test) were much higher at the retail LPM (rLPM) than that at the wLPM (Figure 1), probably because of poultry mixing, aggregation, and extended stay at retail settings. Human $\mathrm{H} 5$ or $\mathrm{H7}$ zoonotic infections clustered in winter, but we observed no correlation ( $\mathrm{p}>0.215$ for both) between temperature (14) and $\mathrm{H} 5$ or $\mathrm{H} 7$ detection rates in chickens or environmental samples at both markets. We did not assess other confounding factors, including market interventions and poultry holding duration.
We evaluated correlations between monthly AIV detection rates in chickens and environmental samples (moderate correlation for $r_{s}>0.5$, at which point environmental samples are considered useful to monitor AIV in chickens). We observed a positive correlation for H5 (Spearman $r_{s}=0.569, p<0.001$ ) and $\mathrm{H} 9$ viruses $\left(\mathrm{r}_{\mathrm{s}}=0.702, \mathrm{p}<0.001\right)$ at the $\mathrm{wLPM}$ and for H5 $\left(\mathrm{r}_{\mathrm{s}}=0.581, \mathrm{p}<0.001\right)$, H7 $\left(\mathrm{r}_{\mathrm{s}}=0.760, \mathrm{p}<0.001\right)$, and $\mathrm{H} 9$ viruses $\left(\mathrm{r}_{\mathrm{s}}=0.685, \mathrm{p}<0.001\right)$ at the rLPM. We examined the use of environmental samples to assess AIV activity in poultry (Table 1). Environmental

Table 1. Sensitivity and specificity of applying environmental samples to assess AIV activity in poultry, based on monthly AIV detection, Guangdong, China, December 2015-July 2018*

\begin{tabular}{|c|c|c|c|c|c|c|}
\hline Market type & Subtype & $\begin{array}{c}\text { Sensitivity, \% } \\
(95 \% \mathrm{Cl}) \dagger\end{array}$ & $\begin{array}{c}\text { Specificity, \% } \\
(95 \% \mathrm{Cl}) \dagger\end{array}$ & $\begin{array}{l}\text { Positive predictive } \\
\text { value, } \%(95 \% \mathrm{Cl}) \dagger\end{array}$ & $\begin{array}{l}\text { Negative predictive } \\
\text { value, } \%(95 \% \mathrm{Cl}) \dagger\end{array}$ & $\begin{array}{c}\text { Accuracy, \% } \\
(95 \% \mathrm{Cl}) \dagger\end{array}$ \\
\hline \multirow[t]{3}{*}{ Wholesale } & $\mathrm{H} 5$ & $45.5(16.8-76.6)$ & $95.2(76.2-99.9)$ & $83.3(39.9-97.4)$ & $76.9(65.8-85.2)$ & $78.1(60.0-90.7)$ \\
\hline & $\mathrm{H} 7$ & $68.4(43.5-87.4)$ & 69.2 (38.6-90.9) & 76.5 (57.6-88.6) & $60.0(41.4-76.1)$ & $68.8(50.0-83.9)$ \\
\hline & $\mathrm{H} 9 \ddagger$ & $100(88.4-100)$ & $0(0-84.2)$ & 93.8 & NA & $93.8(79.2-99.2)$ \\
\hline \multirow[t]{3}{*}{ Retail } & $\mathrm{H} 5$ & $90.0(55.5-99.8)$ & $45.5(24.4-67.8)$ & $42.9(32.7-53.7)$ & $90.9(59.6-98.6)$ & $59.4(40.6-76.3)$ \\
\hline & $\mathrm{H} 7$ & $87.0(66.4-97.2)$ & 66.7 (29.9-92.5) & $87.0(72.3-94.5)$ & $66.7(38.7-86.4)$ & $81.3(63.6-92.8)$ \\
\hline & $\mathrm{H} 9 \S$ & $100(89.1-100)$ & NA & $100(89.1-100)$ & NA & $100(89.1-100)$ \\
\hline
\end{tabular}

*Test results from reverse transcription PCR on bird samples were assumed to be the standard in the analysis. The results may not be applicable to other surveillance systems with more intensive sampling or accurate laboratory testing. AIV, avian influenza virus; NA, not applicable.

†Sensitivity: probability that the environmental samples will test positive when the subtype of AIV is present in chickens on site (true positive rate). Specificity: probability that the environmental samples will test negative when the subtype of AIV is not present (true negative rate). Positive predictive value: probability that the subtype of AIV is present in poultry when environmental samples are tested positive. Negative predictive value: probability that the subtype of AIV is not present in poultry when the environmental samples are tested negative. Accuracy: probability that the presence or absence of AIV in poultry will be correctly determined based on the test results of environmental samples.

‡H9 was detected during every month during the study period in the environmental samples (monthly data can be found in Appendix Table 1 , https://wwwnc.cdc.gov/EID/article/26/3/19-0888-App1.pdf).

$\S \mathrm{H} 9$ was detected during every month during the study period in both the poultry and the environmental samples (monthly data can be found in Appendix Table 2). 
samples collected at the rLPM provided higher sensitivity in detecting $\mathrm{H} 5, \mathrm{H} 7$, or $\mathrm{H} 9$ viruses in poultry than those from the wLPM. Environmental samples were less likely to detect $\mathrm{H} 5$ and $\mathrm{H} 7$ viruses in poultry at the wLPM than at the rLPM (Appendix Tables $1,2)$, possibly because of the low prevalence of infection in birds, a higher poultry turnover rate, and comparatively thorough daily cleaning practices at the wLPM. The lower specificity for H5 at the rLPM may be the result of carryover contamination at the poultry slaughtering area caused by processing birds of other species. The probabilities of accurately detecting the presence or absence of $\mathrm{H} 5, \mathrm{H} 7$, and $\mathrm{H} 9$ subtypes in poultry from environmental samples were comparable for the wLPM $(68.8 \%-93.8 \%)$ and the $\operatorname{rLPM}(59.4 \%-100 \%)$ (Table 1$)$. This finding suggests that environmental samples provided a useful indication of AIV activity in chickens at LPMs. Nevertheless, for H5 and H7 viruses at the wLPM, in only 1 month did all environment samples test positive when bird samples were also positive, demonstrating the need to take a wide range of environment samples.

We investigated correlations between specific environmental samples and monthly $\mathrm{H} 5, \mathrm{H} 7$, and $\mathrm{H} 9$ detection rates in chickens (Figure 2; Appendix Figure 2). At the wLPM, positive rates for $\mathrm{H} 5\left(\mathrm{r}_{\mathrm{s}}=0.515\right.$, $\mathrm{p}=0.003), \mathrm{H} 7\left(\mathrm{r}_{\mathrm{s}}=0.514, \mathrm{p}=0.003\right)$, and H9 $\left(\mathrm{r}_{\mathrm{s}}=0.508\right.$,

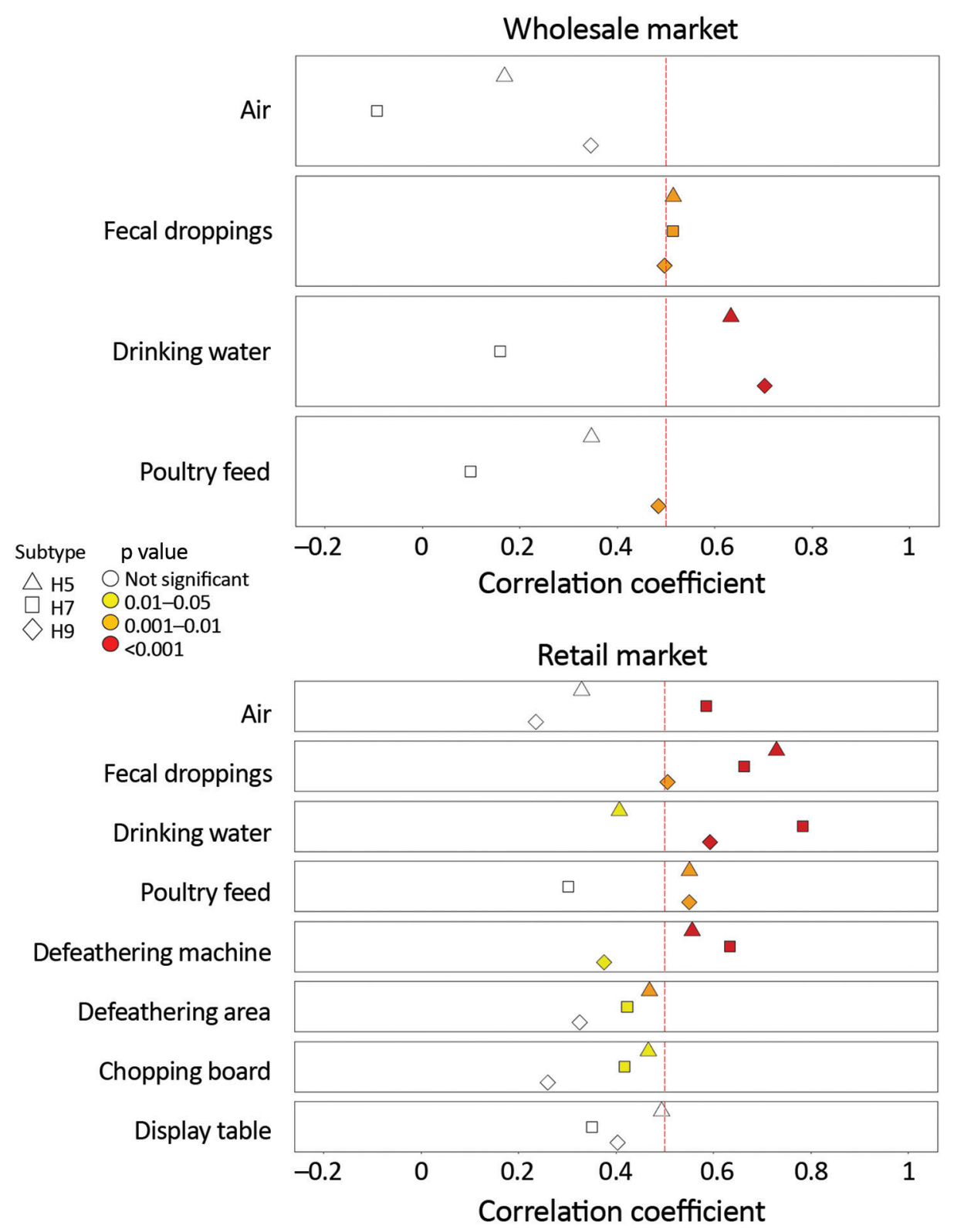

Figure 2. Correlation between AIV detection rates in poultry and environmental samples at live poultry markets (LPMs), Guangdong, China, December 2015-July 2018. Monthly AIV, $\mathrm{H} 5, \mathrm{H} 7$, and $\mathrm{H} 9$ detection rates in chicken and environmental samples were analyzed using Spearman's rank correlation. The vertical red dashed line indicates correlation coefficient $\left(r_{s}\right)$ at 0.5 . Subtypes and significance levels are indicated. AIV, avian influenza virus. 
Table 2. AIV detection rates from chicken and environmental samples collected at a retail LPM, Guangdong, China, December 2015July $2018^{*}$

\begin{tabular}{|c|c|c|c|c|}
\hline \multirow[b]{2}{*}{ Type of samples } & \multirow[b]{2}{*}{ No. samples } & \multicolumn{3}{|c|}{ Median monthly positive rate, $\%(95 \% \mathrm{Cl})$} \\
\hline & & $\mathrm{H} 5$ & $\mathrm{H} 7$ & $\mathrm{H} 9$ \\
\hline Poultry samples $†$ & 1,239 & $0.0(0.0-2.5)$ & $5.8(0.0-15.0)$ & $64.6(55.0-67.5)$ \\
\hline Oropharyngeal & 1,239 & $0.0(0.0-2.5)$ & $5.8(0.0-13.3)$ & $60.0(52.5-67.5)$ \\
\hline Cloacal & 1,239 & $0.0(0.0-2.5)$ & $0.0(0.0-2.5)$ & $20.0(13.2-26.5)$ \\
\hline Environmental samples & 1,734 & $6.2(0.0-11.8)$ & $4.2(1.6-22.0)$ & $73.8(60.0-79.4)$ \\
\hline Poultry holding zone & 965 & $2.9(0.0-6.3)$ & $3.0(0-20.0)$ & $68.2(56.0-75.9)$ \\
\hline Fecal droppings & 424 & $0.0(0.0-7.7)$ & $0.0(0.0-11.1)$ & $58.3(50.0-66.7)$ \\
\hline Drinking water & 364 & $0.0(0.0-8.3)$ & $3.3(0.0-15.4)$ & $83.3(66.7-100.0)$ \\
\hline Poultry feed & 177 & $0.0(0.0-11.1)$ & $0.0(0.0-9.1)$ & $50.0(33.3-70.0)$ \\
\hline Poultry slaughtering zone & 457 & $2.2(0.0-25.0)$ & $6.1(0.0-22.2)$ & $78.6(59.5-87.5)$ \\
\hline Defeathering machine & 250 & $0.0(0.0-20.0)$ & $0.0(0.0-20.0)$ & $86.2(70.0-100.0)$ \\
\hline Defeathering area & 207 & $0.0(0.0-25.0)$ & $0.0(0.0-12.5)$ & $73.2(50.0-87.5)$ \\
\hline Poultry selling zone & 194 & $27.9(0.0-50.0)$ & $0.0(0.0-14.3)$ & $91.2(60.0-100.0)$ \\
\hline Chopping board & 141 & $33.0(0.0-50.0)$ & $0.0(0.0-25.0)$ & $100.0(71.4-100.0)$ \\
\hline Display table & 53 & $0.0(0.0-66.7)$ & $0.0(0.0-14.3)$ & $92.9(25.0-100.0)$ \\
\hline Air§ & 118 & $0.0(0.0-25.0)$ & $0.0(0.0-16.7)$ & $75.0(50.0-100.0)$ \\
\hline
\end{tabular}

${ }^{*} \mathrm{AIV}$, avian influenza virus; LPM, live poultry market; qRT-PCR, quantitative reverse transcription PCR.

†A positive poultry sample may detect AIV in the oropharyngeal samples, cloacal samples, or both by qRT-PCR

łEnvironmental swab specimens were collected within the same poultry stall at LPMs but may not be from the same cage where the chickens were

sampled. Fecal droppings were collected from the ground or cages, drinking water was collected from the water troughs, and poultry feed was sampled from the surface of the bowls or feeders.

§A positive air sample may be positive for AIV by qRT-PCR in any of the 3 size fractions collected by a NIOSH sampler (11). Two to 6 NIOSH samplers were applied monthly to sample air at the retail markets.

$\mathrm{p}=0.003)$ in fecal droppings correlated moderately well with viral prevalence in chickens, whereas drinking water provided the best correlation for $\mathrm{H} 5\left(\mathrm{r}_{\mathrm{s}}=0.633\right.$, $\mathrm{p}<0.001)$ and $\mathrm{H} 9\left(\mathrm{r}_{\mathrm{s}}=0.702, \mathrm{p}<0.001\right)$ (Figure 2) and was more sensitive for H9 (Appendix Figure 3). At the $\mathrm{rLPM}, \mathrm{H} 9$ detection rates in drinking water $\left(\mathrm{r}_{\mathrm{s}}=0.593\right.$, $\mathrm{p}<0.001)$, poultry feed $\left(\mathrm{r}_{\mathrm{s}}=0.550, \mathrm{p}=0.002\right)$, and fecal droppings $\left(\mathrm{r}_{\mathrm{s}}=0.506, \mathrm{p}=0.003\right)$ best correlated with H9 prevalence in chickens; drinking water was most sensitive (Appendix Figure 3). H7 detection rates in drinking water $\left(\mathrm{r}_{\mathrm{s}}=0.784, \mathrm{p}<0.001\right)$, fecal droppings $\left(r_{s}=0.663, p<0.001\right)$, defeathering machines $\left(r_{s}=0.634\right.$, $\mathrm{p}<0.001)$, and air $\left(\mathrm{r}_{\mathrm{s}}=0.585, \mathrm{p}<0.001\right)$ best correlated with $\mathrm{H} 7$ prevalence in chickens. The $\mathrm{H} 5$ detection rates in fecal droppings $\left(r_{s}=0.729, p<0.001\right)$, defeathering machines $\left(\mathrm{r}_{\mathrm{s}}=0.556, \mathrm{p}<0.001\right)$, and poultry feed $\left(r_{s}=0.550, p=0.02\right)$ best correlated with $\mathrm{H} 5$ prevalence in chickens. Collectively, these results suggest that fecal droppings may provide a good estimation for $\mathrm{H} 5, \mathrm{H} 7$, and $\mathrm{H} 9$ prevalence in chickens at LPMs and that drinking water can be more sensitive in some settings and useful for determining virus contamination in LPMs. For viruses present at low prevalence (e.g., $\mathrm{H} 5)$, low sensitivity is expected.

We summarized $\mathrm{H} 5, \mathrm{H} 7$, and $\mathrm{H} 9$ detection rates in various environmental samples at the rLPM (Table 2). H5 virus was most frequently detected from poultry selling zones (median monthly positive rate $27.9 \%, 95 \%$ CI $0 \%-50 \%$ ), especially from chopping boards (33\%, 95\% CI 0\%-50\%), whereas $\mathrm{H} 7$ virus was most frequently detected from poultry slaughtering zones $(6.1 \%, 95 \%$ CI $0 \%-22.2 \%)$, especially from defeathering machines. $\mathrm{H} 9$ virus was frequently detected from all sampling sites. However, we found no clear difference in environmental sites for detecting H5, H7, or H9 (Appendix Tables 1,2).

\section{Conclusions}

AIV detection rates in environmental samples correlated moderately with AIV activity in chickens at LPMs. Environmental sampling at rLPMs provides greater sensitivity in detecting $\mathrm{H} 5, \mathrm{H} 7$, and $\mathrm{H} 9$ AIV in poultry than that at the wLPMs and should be included as routine surveillance to monitor AIV activity. At the rLPM, H5 and H7 viruses were most frequently detected from poultry selling and poultry slaughtering areas, whereas the highly prevalent $\mathrm{H} 9$ viruses were detected frequently at poultry holding, slaughtering, and selling areas. Environmental samples with the highest detection rate for $\mathrm{H} 5, \mathrm{H} 7$, and $\mathrm{H} 9$ viruses may not provide the best indication of virus activity in poultry, however. Some market stalls containing viruses with low prevalence would be misclassified if only environmental or bird samples were collected. To detect viruses expected to be present at low prevalence, environmental samples should be collected from multiple sites in each market stall, including samples from holding, processing, and selling areas.

This study was supported by contract HHSN272201400006C from the United States Department of Health and Human Services and the Theme-based Research Scheme (project no. T11-705/14N) from the Research Grants Council, Hong Kong SAR, China. 


\section{About the Author}

Ms. Cheng is a postgraduate student at the University of Hong Kong. Her primary research interest is avian influenza epidemiology at live poultry markets. Dr. Wu is the chief technician for respiratory pathogens at Guangdong Provincial Center for Disease Control and Prevention, Guangdong, China. Her research interest is in monitoring human infection risk by avian influenza viruses at the human-poultry interface.

\section{References}

1. Peiris JS, Cowling BJ, Wu JT, Feng L, Guan Y, Yu H, et al. Interventions to reduce zoonotic and pandemic risks from avian influenza in Asia. Lancet Infect Dis. 2016;16:252-8. https://doi.org/10.1016/S1473-3099(15)00502-2

2. Cowling BJ, Jin L, Lau EHY, Liao Q, Wu P, Jiang H, et al. Comparative epidemiology of human infections with avian influenza A H7N9 and H5N1 viruses in China: a population-based study of laboratory-confirmed cases. Lancet. 2013;382:129-37. https:/ / doi.org/10.1016/ S0140-6736(13)61171-X

3. Jiang H, Wu P, Uyeki TM, He J, Deng Z, Xu W, et al. Preliminary epidemiologic assessment of human infections with highly pathogenic avian influenza $\mathrm{A}(\mathrm{H} 5 \mathrm{~N} 6)$ virus, China. Clin Infect Dis. 2017;65:383-8. https:/ / doi.org/ 10.1093/cid/cix334

4. Wu J, Ke C, Lau EHY, Song Y, Cheng KL, Zou L, et al. Influenza $\mathrm{H} 5 / \mathrm{H} 7$ virus vaccination in poultry and reduction of zoonotic infections, Guangdong Province, China, 2017-18. Emerg Infect Dis. 2019;25:116-8. https:/ / doi.org/10.3201/ eid2501.181259

5. Leung YHC, Zhang LJ, Chow CK, Tsang CL, Ng CF, Wong CK, et al. Poultry drinking water used for avian influenza surveillance. Emerg Infect Dis. 2007;13:1380-2. https:/ / doi.org/10.3201/eid1309.070517

6. Wang X, Wang Q, Cheng W, Yu Z, Ling F, Mao H, et al. Risk factors for avian influenza virus contamination of live poultry markets in Zhejiang, China during the 2015-2016 human influenza season. Sci Rep. 2017;7:42722. https:/ / doi.org/10.1038/srep42722
7. Yuan J, Lau EH, Li K, Leung YH, Yang Z, Xie C, et al. Effect of live poultry market closure on avian influenza A(H7N9) virus activity in Guangzhou, China, 2014. Emerg Infect Dis. 2015;21:1784-93. https:// doi.org/10.3201/eid2110.150623

8. Kang M, He J, Song T, Rutherford S, Wu J, Lin J, et al. Environmental sampling for avian influenza A(H7N9) in live-poultry markets in Guangdong, China. PLoS One. 2015;10:e0126335. https://doi.org/10.1371/journal. pone.0126335

9. Fang S, Bai T, Yang L, Wang X, Peng B, Liu H, et al. Sustained live poultry market surveillance contributes to early warnings for human infection with avian influenza viruses. Emerg Microbes Infect. 2016;5:1-8. https:/ / doi.org/ 10.1038/emi.2016.75

10. Kim Y, Biswas PK, Giasuddin M, Hasan M, Mahmud R, Chang YM, et al. Prevalence of avian influenza A(H5) and $\mathrm{A}(\mathrm{H} 9)$ viruses in live bird markets, Bangladesh. Emerg Infect Dis. 2018;24:2309-16. https://doi.org/10.3201/ eid2412.180879

11. Lindsley WG, Green BJ, Blachere FM, Martin SB, Law BF, Jensen PA, et al. Sampling and characterization of bioaerosols. In: NIOSH manual of analytical methods, 5th edition. Cincinnati: National Institute for Occupational Safety and Health, Centers for Disease Control and Prevention; 2017.

12. Chinese Center for Diseases Control and Prevention. Avian influenza surveillance programme [cited 2019 June 17]. http://www.chinaivdc.cn/cnic/zyzx/jcfa/201605/ W020160520546618208788.pdf

13. World Health Organization. WHO information for the molecular detection of influenza viruses; 2017 [cited 2019 June 8]. https://www.who.int/influenza/gisrs_laboratory/ WHO_information_for_the_molecular_detection_of_ influenza_viruses_20171023_Final.pdf

14. National Oceanic and Atmosphere Administration. Station data inventory, access and history [cited 2019 June 8]. https://www.ncdc.noaa.gov/cdo-web/datasets/GHCND/ stations/GHCND:CHM00059287/detail

Address for correspondence: Hui-Ling Yen or Eric Ho-Yin Lau, The University of Hong Kong School of Public Health, Li Ka Shing Faculty of Medicine, 21 Sassoon Road, Hong Kong SAR, China; email: hyen@hku.hk or ehylau@hku.hk 